\title{
An instrument for dimensional diagnosis of a child's constitution (ICC)
}

\begin{abstract}
Developmental disorders present themselves with complex problems that may threaten a child's development. In every child a disorder shows itself in a unique way, which makes it necessary to individualize. The objective of this preliminary study is to develop an instrument that provides a dimensional diagnosis by mapping the degree of (dis)balance in three domains of child development. The instrument is based on anthroposophic anthropology and typology. The instrument will be usable in all kinds of care for children with developmental disorders. The typology of a child's constitution was operationalized using concept mapping and consensus building with experts. Preliminary tests of the psychometric properties of the instrument were applied on children with developmental disorders in a pilot study in Dutch healthcare. The Instrument for diagnosis of a Child's Constitution (ICC) developed in this study consists of two parts. Part I contains 36 polar formulated items in three subscales of 12 items and is to be completed by healthcare professionals. Part II consists of three VAS scales (Visual analogue scales) and is to be completed y a practitioner. The outcome (the scores of Part I and II) forms a profile of the child's constitution, showing the (dis) balance in three domains of child development. A pilot study with 38 children shows positive face validity, and moderate internal consistency and inter-rater reliability of the ICC.
\end{abstract}

The ICC has been developed as a diagnostic instrument to assess individualized dimensional diagnosis of children with a developmental disorder. Future studies will focus on validation of the instrument.

Keywords: child constitution, instrument development, dimensional diagnostics, developmental disorders, anthroposophic anthropology
Volume II Issue 2 - 2018

\author{
Niemeijer MH,' Baars EW, ${ }^{2}$ Hoekman J, ${ }^{3}$ \\ Ruijssenaars AJJM. ${ }^{4}$ \\ Hogeschool Leiden, Anthroposophical Health Care \\ Research Group, Netherlands \\ Lector Anthroposophical Health Care Hogeschool, \\ Netherlands \\ Universiteit Leiden, Netherlands \\ Hoogleraar Faculteit Gedrags- en \\ maatschappijwetenschappen RU Groningen, \\ Netherlands
}

Correspondence: Hogeschool Leiden, Anthroposophical Health Care Research Group, Zernikedreef I I, 2333CK Leiden, Nederland,Email mhn@planet.nl

Received: February 0I, 20I8| Published: March 22, 2018

\section{Introduction}

\section{Developmental disorders}

Developmental disorders include a broad range of psychological and physical symptoms by which children differ from what is generally considered as normal. These neuro-developmental disorders ${ }^{1}$ have a pervasive effect on a child's development and functioning; they may affect it permanently in multiple developmental domains. The following disorders are mostly included: language/speech, learning and motoric disorders, Autism Spectrum Disorder (ASD), Attention Deficit Hyperactivity Disorder (ADHD), Obsessive Compulsive Disorder, Conduct Disorder and tic disorders. Intellectual disabilities and genetic syndromes, like Down's syndrome, are included too. Some clinicians consider early traumatic experiences that affect the development of the child's capacity of building attachments with others also to be a developmental disorder. ${ }^{2}$

The prevalence of developmental disorders seems to be increasing. In American research amongst children between the ages of 3 and 17, Boyl ${ }^{3}$ found an increase in the prevalence from $12.48 \%$ to $15.04 \%$ between the periods of 1997/1999 to 2006/2008. In this study ADHD, ASD, learning disorders, sensory disorders, intellectual disabilities, epilepsy and motoric disorders were included. The prevalence of ASD increased from $0.19 \%$ to $0.74 \%$ in the aforementioned period, ADHD from $5.69 \%$ to $7.57 \% .^{3}$

Developmental disorders rarely occur in isolation. There is often comorbidity, such as between learning disorders and ASD. ${ }^{4}$ More than $70 \%$ of the children with ASD have at least one comorbid disorder ${ }^{5}$ and $40 \%$ have two or more. ${ }^{6}$

Kaplan ${ }^{7}$ considers the term 'comorbidity' of limited value in relation to developmental disorders; they are atypical and neurological dysfunctions that lead to a continuum of disorders. In each child a developmental disorder has a unique presentation. In the DSM- $5^{8}$ the categorical structure does not always fit the realities of clinical practice and scientific research. Therefore steps towards a more dimensional approach and individualisation in diagnosis are preferred.

\section{Diagnostics}

Theories relating to developmental disorders are multidisciplinary with contributions from the field of developmental psychology ${ }^{9}$ and medicine. ${ }^{10}$ This links well with an interdisciplinary approach in the examination and diagnostics of children with a possible developmental disorder. ${ }^{11}$ This way of diagnostics consists of the classification of the disorder and mapping out the child's individual functioning. 
Classifying disorders in well-defined categories have led to the development of protocol- and evidence-based treatments for similar problems. ${ }^{12}$ A disadvantage of the categorical classification is the all-or-nothing threshold concerning the number of criteria that must be adhered to in order to establish the presence of a disorder. ${ }^{13}$ Developmental disorders manifest themselves in varying degrees in different developmental domains. ${ }^{14}$ The individual situation is better portrayed by a dimensional approach. ${ }^{15,16}$

\section{Constitutional diagnostics}

In anthroposophically inspired healthcare for children with developmental disorders determining the constitution is a method to map the child's individual situation. ${ }^{17}$ This method has derived from a typology of the constitution which has its basis in anthroposophic anthropology. ${ }^{18-20}$

The concept of "type", used here, may be characterized as a dynamic and plastic complex of ways constituting similar but not identical living organisms..$^{21}$ The 'type' functions as the active designer which expresses itself in form and function of organisms and organs. The 'type' is for living nature what laws of nature, such as gravity, are for dead nature. As such, the 'type' is invisible to physical senses. It applies to the individual organisms that are manifestations of a 'type'. A living organ(ism) is a unique manifestation of a 'type'.

In the typology of the constitution three organs are distinguished as domains of development in a child's functioning, a cognitive, an affective and a conative domain. In these domains the typology focuses on a designer, a 'type'. This type constitutes bio-pychosocial processes of development in each domain, with polar one-sidedness on both extremes of a continuum. In the constitutional diagnostics of a child the degree of (im-)balance on the continuum in the three domains is identified and mapped. ${ }^{19}$

On the continuum in the domain of cognitive functioning the quality of perception, thinking and remembering are the central theme. On the one hand, this consists of the ability of forming thoughts and memories. On the other hand, letting go of these thoughts and forgetting them. The domain of affective functioning covers the experience and expression of feelings and emotions and the ability to pull back and close oneself off from the environment emotionally. The domain of conative functioning is about movement and mobility. On the one hand the ability of slowing down and being passive and on the other hand the capacity of moving and being active.

A child's functioning can be mapped on a continuum for each of these domains, with one- sidedness on either sides of a healthy middle. The one-sidedness of functioning in the three developmental domains is expressed by six characterizing descriptions. They consist of a verb and a noun:

a. Densifying/Obsessive versus Dissolving/Forgetful for the cognitive developmental domain

b. Closing/Clenched versus Opening/Outflowing for the affective developmental domain

c. Decelerating/Heavy versus Accelerating/Light for the conative developmental domain

Each child has its own degree of (im-)balance in the continua of the three developmental domains, according to her or his constitution.

\begin{tabular}{llll}
\hline Child development domains & Cognitive & Affective & Conative \\
\hline $\begin{array}{l}\text { 'Type', designing } \\
\text { biopsychosocial } \\
\text { processes } \\
\text { Child functioning }\end{array}$ & $\begin{array}{l}\text { quality of perception, } \\
\text { thinking and remembering }\end{array}$ & $\begin{array}{l}\text { experience and } \\
\text { expression of feelings } \\
\text { and emotions } \\
\text { Closing/Clenched }\end{array}$ & $\begin{array}{l}\text { about movement and } \\
\text { mobility }\end{array}$ \\
& Densifying/Obsessive & Decelerating/Heavy \\
& Dissolving/Forgetful & Opening/Outflowing & Accelerating/Light \\
\hline
\end{tabular}

\section{Theoretical framework}

A child's development occurs as a transactional process 9 in a continuous interaction between organism and environment, both of which are continuously changing. ${ }^{22,23} \mathrm{~A}$ developmental disorder intervenes in this interaction. A child's organism uses self-regulating capacities, such as resilience, in order to adapt and recover balance in functioning. ${ }^{24}$

Recognising these capacities is linked to attitudes regarding health as a dynamic phenomenon, as the capacity of adapting and maintaining autonomy in the light of physical, emotional and social challenges. ${ }^{25}$ The typology of the constitution is built on this concept of health. Thereby, the three developmental domains that are present in this typology - the cognitive, affective and conative domain - are known from psychology ${ }^{26,27}$ and psychiatric research. ${ }^{28,29}$
The term 'constitutional typology' refers to the basis of constitutional characteristics. In medical literature, the term 'constitution' is used as a reference to the predisposition, the genetic constitution of the child. Genetic constitution is responsible for the development of structure and functions of an organism. ${ }^{30}$ In this conception constitution is an immutable, static fact of a child's predisposition. However, in constitutional typology constitution is a dynamic phenomenon. A child's constitution changes during life under the influence of the environment and the child's personality. In this meaning constitution may be influenced by treatment.

As an indicator of the coherence between predisposition and biopsychosocial phenomena the term constitution seems to be losing its meaning, in favour of the term 'temperament'. This is related to descriptions of temperament as predisposition based individual differences in behaviour. ${ }^{31}$ Temperament consists of personality 
characteristics that have a genetic and neurobiological foundation. ${ }^{32}$ There are similarities and differences between the conception and role of 'constitution' and 'temperament' in literature. One similarity is that in constitutional features constitution refers to coherence in predisposition and bio-psychosocial processes; comparable to temperament. ${ }^{18,19,33}$ A difference is the relation to developmental disorders. Temperament is considered to be a personality trait that protects the child, or may trigger the risk of developing disorders. ${ }^{34}$ The conception of constitution used here consists of a child's actual bio- psychosocial functioning, including a possible developmental disorder.

\section{Aim and research questions}

Aim of this study is to develop a measuring instrument to determine the degree of (im-) balance in a child's constitution. This study supports the scientific basis of Integrative Healthcare ${ }^{35}$ and of anthroposophically inspired healthcare in particular. ${ }^{36}$ The study is socially relevant because it contributes to the further development of anthroposophic healthcare which is focused on the situation of the individual child. Previous steps in the scientific justification were a methodical description of healthcare ${ }^{17}$ and of the typology of the constitution. ${ }^{19,20,37}$ The questions of this study:

a. Which bio-psychosocial phenomena should be included in the instrument?

b. Which design of the instrument fits best the constitutional typology?

c. What are outcomes of investigation into internal consistency, inter- and intra-rater reliability?

\section{Methods}

Concept mapping has been used to answer the first question in a group of experienced professionals. Consensus building with experts was used to determine which items should be included and how the instrument should be designed. A pilot study with the cooperation of practitioners was conducted to answer the third question. Instrumental usability was examined by a questionnaire.

\section{Concept mapping}

Concept mapping is used for the operationalisation of conceptions in (healthcare-based) research. ${ }^{38}$ It entails the generation, prioritisation and clustering of phenomena which by a cluster analysis leads to an overview of the attitudes of the group of people in question. ${ }^{39}$ In this study the written variant of concept mapping ${ }^{40}$ was used in order to generate, prioritise and cluster the characterising bio-psychosocial phenomena concerned for the first research question. For this analysis the Ariadne program ${ }^{5}$ combines statistical techniques, Principal Components Analysis and Hierarchical cluster analysis.

\section{Consensus building}

Consensus in regarding a topic is the agreement between experts, based on empirical study and on their shared professional experience. ${ }^{42}$ In three meetings consensus building with professionals and researchers was realised answering the second question relating to composition and design of the instrument.

\section{Design of the instrument}

The researchers submitted in the consensus group a proposition for the construction of the instrument. In this proposal the principle of polarity was applied; there has been chosen to use measuring scales by which the degree of (im-) balance in a system could be scored. The constitution was made measurable in two ways. In the proposition the first way of measuring the constitution consisted of judging polar formulated phenomena on a seven-point Likert scale, with a range from -3 to +3 . In the instrument this will be indicated in three subscales, one for each of the developmental domains. Whether or not there is a balance or imbalance in a polar formulated phenomenon and the extent to which it is disruptive can be indicated. The score 0 points towards a balance; all other scores indicate a greater or lesser deviation from this balance. This way of measuring is of an analytical nature as the child's scores are determined on the basis of separate phenomena. This way is according to the composition of questionnaires in contemporary regular diagnostics.

The second way of measuring consisted of the clinical evaluation of the child's functioning by the practitioner as to the degree of balance in each of the three developmental domains. Findings in the examination of the child and the characterising descriptions of onesidedness has to be compared. In the instrument this will be indicated on three Visual Analogue Scales (VAS scales). The measuring of VAS scales is of an synthetical nature. It appeals to the practitioner's tacit knowledge ${ }^{41}$ and the capacity to recognise a pattern or 'Gestalt" ${ }^{43}$ and is connected to the method of 'pattern recognition'. ${ }^{17,44}$

\section{Pilot study}

To answer the third question, the instrument was investigated in terms of internal consistency, inter-rater reliability and instrumental usefulness in a pilot study with 38 children. Fifteen practitioners, six doctors and nine remedial educationalists/psychologists cooperated in this pilot study. For each of the 38 children the instrument was completed, the polar-formulated items separately by two professional supervisors and the VAS scale separately by two practitioners, a psychologist and a doctor. They registered also the requested personal information: initials, date of birth and gender, the actual DSM classification and the determined level of functioning as found in a study of the child's intelligence, the date of entry and the practitioner's name and job position.

The internal consistency of the three subscales in the instrument was determined by establishing Cronbach's alpha. The inter-rater reliability was determined by calculating Pearson. Correlations of unweighted sum scores between pairs of evaluators for each of the three subscales in Part I and the three VAS scales in Part II. As criterion for the quality of the internal consistency the Consensus-based Standards for selection of health Measurement Instruments (COSMIN) ${ }^{45}$ gave a Cronbach's alpha of $>.70$; for the inter-rated reliability a Pearson correlation of $>.70$. The instrumental usefulness was investigated by inventorying the experience of respondents using the instrument, and through the determination of the missing values, by which a maximum percentage of $5 \%$ was established. ${ }^{46}$

\section{Results}

\section{Concept mapping}

Experienced professionals: Experienced professionals are considered to be carriers of 'tacit knowledge..$^{41} \mathrm{~A}$ total of 42 people 
were asked to participate in this study: 12 professional supervisors, six artistic therapists, 11 remedial educationalists/psychologists and 13 doctors. Of these 42, 14 people opted out of the study (because of illness, lack of time) and six people did not respond. The remaining group of 22 experts consisted of three professional supervisors, four therapists, eight remedial educationalist/psychologists and seven doctors. On average these professionals had been working in healthcare for 16.2 years, with a range of 6.4 to 21.3 years.

Two rounds of questionnaires: The 22 participants received questionnaires in two rounds. All of the participants (100\%) responded to the first questionnaire; the second questionnaire had a response rate of $63.6 \%$ (14 participants). In the first round the participants were asked which bio-psychosocial phenomena they considered typical for each constitutional domain. In the second round the participants were asked to prioritise the gathered phenomena from the first round. In addition they were asked to categorise the connected phenomena in clusters. Priorisation could be given on a five-point scale, ranging from low (1) to high (5). Phenomena with an average priorisation higher than 3.5 were considered important for the diagnostics of the constitution.

Inventory and prioritization: The selected number of phenomena, which were generated by the experienced experts in the first questionnaire and received an average prioritisation equal to or greater than 3.5 on the five-point scale in the second round, were:

a. Densifying/Obsessive -Dissolving/Forgetful: in the first round: 38 and 36; and in the second round: 21 (46.6\% of the number generated in the first round) and $17(47.2 \%)$;

b. Closing/Clenched- Opening/Outflowing: 60 and 59 in the first round; in the second round: $34(56.6 \%)$ and 26 (44.1\%);

c. Decelerating/Heavy - Accelerating/Light: 40 and 60 in the first round; in the second round: $17(42.5 \%)$ and 29 (48.3\%).

\section{Clustering}

The selected phenomena were processed into an average clustering by using the Ariadne program with the Principal Components Analysis and Hierarchical cluster analysis. The choice for two clusters presented preferable options for interpretation, and thereby an ordering for selection of the items which were included in the instrument. The first cluster contained psychological phenomena and the second cluster consisted of biological/physiological phenomena in the developmental domains they were related to.

\section{Consensus building}

Agreement was reached in the consensus group with the experts as to the researchers' proposal about the construction and design of the instrument as described in the section Methods. The Instrument to determine the Child's Constitution (ICC) will consist of two parts: Part I contains polar formulated items, for the assessment on a sevenpoint Likert scale. Part II consists of three VAS scales, which indicate the degree of balance or imbalance in the developmental domains. For Part I the number of items for each of the three developmental domains is maximized at 12. Items are selected from the two clusters of phenomena, with a minimum of two items per cluster. The selection of the items is according to the ranking of prioritisation. For Densifying/Obsessive versus Dissolving/Forgetful, ten items from the first cluster are selected, and two items from the second cluster.
For both the Closing/Clenched versus Opening/Out flowing and the Decelerating/Heavy versus Accelerating/Light polarities, nine items are selected from the first cluster and three items from the second cluster.

The manual of the ICC indicates that for registering the child's functioning the month prior to the moment of entry should serve as a guideline. Part I is to be completed by people who are professionally involved in the care of the child. Part II is to be completed by a practitioner responsible for diagnostics. In order to complete the three VAS scales of Part II a characterising description of the three constitutional types has been formulated.

\section{Pilot study}

\section{The pilot group}

The ICC was used in order to diagnose 38 children/adolescents: 10 girls and 28 boys. Their average age was 10.0 years (range: $7-$ 16). Of these children, 14 were classified as having a disorder in the Autistic Spectrum, six had Multi complex Developmental Disorder (McDD), five ADHD, three an Attachment disorder and one child had Down's syndrome. The nine other children were diagnosed with an intellectual disability. The children's level of functioning varied from averagely gifted (five children) to severely mentally disabled (one child); 17 children functioned at a moderately mentally retarded level, 11 children had a slight mental disability and four children had a moderate mental disability. Seven of the children and adolescent were in day-care treatment; the remaining 31 were receiving clinical treatment.

\section{Internal consistency}

For Part I as a whole Cronbach's alpha is .79. For the three subscales of Part I Cronbach's alpha is .64 (Closing/Clenched - Opening/ Outflowing); .67 (Densifying/Obsessive - Dissolving/Forgetful); and .76 (Decelerating/Heavy - Accelerating/Light).

\section{Densifying/Obsessive - Dissolving/Forgetful $\quad .66 * *$ \\ Closing/Clenched - Opening/Outflowing .69** \\ Decelerating/Heavy - Accelerating/Light $\quad .82 * *$}

The Pearson correlations for the three VAS scales of Part II:

$\begin{array}{ll}\text { Densifying/Obsessive - Dissolving/Forgetful } & .44^{* *} \\ \text { Closing/Clenched - Opening/Outflowing } & .25 \\ \text { Decelerating/Heavy - Accelerating/Light } & .47\end{array}$

Decelerating/Heavy - Accelerating/Light

Significance: ${ }^{* *} \mathrm{p}<.01$ :

\section{Instrumental usefulness}

The number of missing values in the 76 completed instruments was 45. In Part I of the instrument 42 missing values were counted, spread over 19 of the 36 items. Concerning Part II, in the VAS scales there were 3 missing values. In total there were 45 missing values for 76 (number of filled out instruments: 38 children x 2) x 39 (number of items: 36 in Part I +3 in Part II) $=2.964$ items; a percentage of $1.51 \%$.

The practitioners and supervisors indicated that the seven-point Likert scale in Part I provided sufficient room for differentiating in answering the questions. Not all questions could be responded by all supervisors on the basis of their personal experience. This applied to questions regarding physical functioning, which were intended for the supervisors working in the day care treatment and artistic therapists. 
None of the practitioners added any remarks in the characterizing description of the constitutional types in the manual.

The following modifications were made to the instrument following the findings relating to the instrumental usefulness: four body oriented items in Part I of the instrument, which had not been filled out by all supervisors, were made optional.

\section{Discussion}

This preliminary study is about the development of the Instrument to determine the Child's Constitution (ICC) for the dimensional diagnostics of children with a developmental disorder. The selection of items for the instrument was made by concept mapping and consensus building with 22 experienced experts who had been working in healthcare for 16.2 years on average. This has resulted in an instrument that consists of three developmental domains and two sections. Part I contains 12 polar formulated items for each of the three domains and is to be completed by professional supervisors. Part II has a VAS-scale for each of the three domains and shows the clinical evaluation of the practitioner responsible for the child's diagnosis. The terminology that is used in the instrument makes it suitable for application in all types of care for children with developmental disorders. In a pilot study with 38 children/adolescents the internal consistency, the inter-rater reliability and instrumental usefulness were investigated. Cronbach's alpha is good for the entire instrument (.79) and 'mediocre' to 'good' for the three subscales of Part I (.64 - . 76). The Pearson correlation for the inter-rated reliability of the three subscales of Part I ranges between .66 and .82; all three are significant $(\mathrm{p}<.01)$. For the three VAS scales in Part II the correlations are low; in the .25 to .47 range. Except for the subscale Closing/ Clenched-Opening/Out flowing, these are statistically significant $(p<.01)$. Investigation of the instrumental usability has led to some modification of the instrument: four items in Part I of the instrument were made optional. These are body oriented biological/physiological items, which cannot be judged by all supervisors, as shown by the number of missing values per item. The number of missing values remains far below the set maximum of $5 \%$ as it is only a percentage of $1.51 \%$. All 36 items of Section I were maintained.

One limiting factor of the study is that the constitutional approach is founded on anthroposophical anthropology of which the philosophical and empirical justification of the theoretical framework are still developing. ${ }^{39}$ A second limiting factor concerns the quality of the pilot study into the validity and reliability of the developed instrument. The pilot group was small and not randomly composed, nor were all aspects of validity and reliability tested.

\section{Conclusion}

Despite its small flaws the ICC in this phase of its development is already of importance to anthroposophic daily practice. It facilitates individualization of diagnostics and individual choices in child oriented treatments. Additionally it contributes to the explication and operationalisation of anthroposophic conceptions and, by doing so, it adds to further scientific foundation of anthroposophically inspired healthcare. Generally speaking, the construction of the ICC with the polar formulated items is an example of a questionnaire which is based on a dynamic healthcare concept.

Subsequent steps that will be taken in the developmental process of the instrument are research into the reliability, validity and responsiveness of the instrument, and further theoretical justification of the constitutional approach towards healthcare.

\section{Acknowledgment}

For this study no funding was received. Ethical approval was not required. The study was conducted by professionals involved in diagnosing the children. The pilot study did not bother the children nor did it disturb their care.

\section{Conflict of interest}

Authors declare there is no conflict of interest towards this manuscript.

\section{References}

1. American Psychiatric Association. Diagnostic and Statistical Manual of Mental Disorders (DSM-5®). American Psychiatric Publ; 2013.

2. Van der Kolk BA. Developmental Trauma Disorder. In: Psychiatric Annals: 2005; p. 401-408.

3. Boyle CA, Boulet S, Schieve LA, et al. Trends in the prevalence of developmental disabilities in US children, 1997-2008. Pediatrics. 2011;127(6):1034-1042.

4. Kaplan B, Crawford S, Cantell M, et al. Comorbidity, co- occurrence, continuum: What's in a name? Child Care Health Dev. 2006;32:723-731.

5. Simonoff E, Pickles A, Charman T, et al. Psychiatric disorders in children with autism spectrum disorders: prevalence, comorbidity, and associated factors in a population-derived sample. J Am Acad Child Adolesc Psychiatry. 2008;47(8): 921-929.

6. Matson JL, Nebel-Schwalm MS. Comorbid psychopathology with autism spectrum disorder in children: An overview. Research in developmental disabilities. 2008;28(4):341-352.

7. Kaplan BJ, Dewey DM, Crawford SG, et al. The Term Comorbidity Is of Questionable Value in Reference to Developmental Disorders Data and Theory. J Learn Disabil. 2001;34(6):555-565.

8. American Psychiatric Association. Diagnostic and Statistical Manual of Mental Disorders (DSM-5®). American Psychiatric Pub: USA; 2005.

9. Pennington BF. From single to multiple deficit models of developmental disorders. Cognition. 2006;101(2):385-413.

10. Morton J. Understanding developmental disorders: A causal modelling approach. Oxford: Blackwell publishers; 1983.

11. Verhulst FC, Verheij F. Kinder- en Jeugdpsychiatrie, Onderzoek en diagnostiek. Assen: Van Gorcum; 2009.

12. Braet C, Bögels SM. Protocollaire behandelingen voor kinderen en adolescenten met psychische klachten. Amsterdam: Boom; 2013.

13. Jongedijk RA. Psychiatrische diagnostiek en het DSM-systeem. Tijdschrift voor psychiatrie. 2001;43(5):309-320.

14. Rutter M. Research review: Child psychiatric diagnosis and classification: concepts, findings, challenges and potential. J Child Psychol Psychiatry. 2011;52(6):647-660.

15. Hudziak JJ, Achenbach TM, Althoff RR, et al. A dimensional approach to developmental psychopathology. Int $J$ Methods Psychiatr Res. 2007;16(S1):S16-S23.

16. Ruijssenaars AJJM, van den Bergh PM, van Drenth JML. Orthopedagogiek. Ontwikkelingen, theorieën en modellen. Antwerpen/Apeldoorn: Garant; 2012. 
17. Baars E. Goede zorg: een antroposofische benadering van ethische uitgangspunten en methodische aspecten van goede zorg. Zeist: Christofoor; 2005.

18. Steiner R. Heilpädagogischer Kurs. Dornach: Rudolf Steiner Taschenbücher aus dem Gesamtwerk.1924.

19. Niemeijer MH, Gastkemper M. Ontwikkelingsstoornissen bij kinderen Assen: Van Gorcum; 2009.

20. Göschel JC. Der biografische Mythos als pädagogisches Leitbild. Dornach Verlag am Goetheanum; 2012.

21. Van der Bie G. holeness in Science. A methodology for pattern recognition and clinical intuition. From the series: Bolk's Fundamental Companions. Driebergen: Louis Bolk Instituut; 2012.

22. Sameroff A. The transactional model. USA: American Psychological Association; 2012

23. Bronfenbrenner U, Morris PA. The bioecological model of human development. Handbook of child psychology; 2006.

24. Luthar SS, Cicchetti D, Becker B. The construct of resilience: A critical evaluation and guidelines for future work. Child Dev. 2000;71(3):543-562.

25. Huber M, Knottnerus JA, Green L, et al. How should we define health? BMJ. 2011;343:d4163.

26. Pervin LA, John OP. Handbook of personality: Theory and research. Elsevier; 1999.

27. Dai DY, Sternberg RJ. Motivation, emotion, and cognition: Integrative perspectives on intellectual functioning and development. UK: Routledge; 2004.

28. Dennis M, Simic N, Bigler ED, et al. Cognitive, affective, and conative theory of mind (ToM) in children with traumatic brain injury. Dev Cogn Neurosci. 2013;5:25-39.

29. Hengeveld MW, Schudel WJ. Het psychiatrisch onderzoek (3de druk). Tijdschrift voor Psychiatrie. 2004;46(12):823-824.

30. Siegel DJ. The developing mind: How relationships and the brain interact to shape who we are. New York: Guilford Press; 2012.

31. Nigg JT. Temperament and developmental psychopathology. J Child Psychol Psychiatry. 2006;47(3-4):395-422.

32. Whittle S, Allen NB, Lubman DI, et al. The neurobiological basis of temperament: towards a better understanding of psychopathology. Neurosci Biobehav Rev.2006;30(4):511-525.
33. Niemeijer MH, Baars EW. Beeldvormende diagnostiek van de kinderlijke constitutie. Driebergen: Louis Bolk Instituut; 2006.

34. De Pauw SS, Mervielde I. Temperament, personality and developmental psychopathology: A review based on the conceptual dimensions underlying childhood traits. Child Psychiatry Hum Dev. 2010;41(3):313-329.

35. http://www.imconsortium.org

36. Kienle GS, Kiene H, Albonico HU. Anthroposophic medicine effectiveness, utility, costs, safety. New York: Schattauer Verlag; 2006.

37. Grimm R, Kaschubowski G. Kompendium der anthroposophischen Heilpädagogik. Basel: Reinhardt; 2008.

38. Trochim W M. An introduction to concept mapping for planning and evaluation. Evaluation and program planning. 1989;12(1):1-16.

39. Swanborn PG. Evalueren: het ontwerpen, begeleiden en evalueren van interventies: een methodische basis voor evaluatie-onderzoek. Amsterdam: Boom; 2007.

40. Häder M, Häder S. Die Delphi-Methode als Gegenstand methodischer Forschungen. In Die Delphi-Technik in den Sozialwissenschaften. 1991;11-31.

41. Polanyi M. Tacit knowledge. Knowledge in organizations. 1997;135-146

42. Kaasenbrood A. Consensus als criterium. De ontwikkeling, de verspreiding en het gebruik van richtlijnen voor goed psychiatrisch handelen. Utrecht: NcGv; 1995.

43. Daston L, Galison P. Objectivity. Brooklyn. New York: Zone Books; 2007.

44. Stolper E, Van de Wiel M, Van Royen P, et al. Gut feelings as a third track in general practitioners' diagnostic reasoning. $J$ Gen Intern Med. 2011;26(2):197-1203.

45. Terwee CB1, Bot SD, de Boer MR, et al. Quality criteria were proposed for measurement properties of health status questionnaires. J Clin Epidemiol. 2007;60(1):34-42.

46. Schafer JL. Multiple imputation: a primer. Stat Methods Med Res. 1999;8(1):3-15. 